\title{
Intracerebral Transplants and Memory Dysfunction: Circuitry Repair or Functional Level Setting?
}

\author{
Bruno Will, ${ }^{\dagger}$ Christian Kelche and Jean-Christophe Cassel \\ Laboratoire de Neurociences, Comportementales et Cognitives \\ LN2C UMR7521 ULP/CNRS, 12 rue Goethe 67000 Strasbourg, France
}

\begin{abstract}
Intracerebral grafting techniques of fetal neural cells have been used essentially with two main types of lesion paradigms, namely damage to long projection systems, in which the source and the target are clearly separate, and damage to neurons that are involved in local circuits within a small (sub)region of the brain. With the first lesion paradigm, grafts placed homotopically (in the source) are not appropriate because their fibers grow poorly through the host parenchyma and fail to reach their normal target. To be successful, the grafts must be placed ectopically in the target region of the damaged projection systems, where generally they work as level-setting systems. Conversely, with the second paradigm, the grafts are supposed to compensate for a local loss of neurons and must be placed homotopically to induce functional effects that are based on the reconstruction of a point-topoint circuitry. By inserting a biological or artificial bridging-substrate between the source and the target of long projection systems, it might be possible to combine the positive effects of both homotopic and ectopic grafting by achieving both target reinnervation and normal control of the grafted neurons within the source area. These issues are illustrated and discussed in this review.
\end{abstract}

\footnotetext{
${ }^{\dagger}$ Corresponding author:

Tel: (33) 3883582 38; Fax: (33) 388358442

e-mail : bruno.will@psycho-ulp.u-strasbg.fr
}

\section{KEYWORDS}

acetylcholine, frontal cortex, graft, hippocampus, hydrogel, serotonin

\section{INTRODUCTION}

Over the last two decades, many clinical trials using intracerebral transplants have been conducted in human beings to alleviate neurological disorders. Most trials were carried out in patients with Parkinson's disease (PD). Some of these studies, especially those using grafts of dopaminergic neurons from human fetuses, showed that the transplanted neurons can survive in a diseased brain and may improve motor function in the patients (for example, Hitchcock et al., 1988; Lindvall et al., 1988, 1989, 1990; Freed et al., 1990; Madrazo et al., 1988, 1990; Spencer et al., 1992; Peschanski et al., 1994; Defer et al., 1996). Alterations of motor function are not the only symptoms exhibited by PD patients. When compared with healthy subjects, even nondemented and still untreated PD patients show, for instance, an impairment of some memory functions (for example, Lavernhe et al., 1989; Dubois et al., 1991), although when compared with patients with Alzheimer's disease, even demented PD patients show some preserved memory functions. Nevertheless, in the literature concerning transplantation in PD patients, only a few studies have assessed cognitive functions in addition to evaluating motor capabilities. The lack of cognitive assessment in PD patients with transplants is 
surprising if one considers that a relation between motor and cognitive impairments has been repeatedly found in such patients (for example, Mayeux and Stern, 1983; Growdon et al., 1990).

Furthermore, the number of studies assessing the neuropsychological outcome of transplantation surgery in PD patients is scant. These studies have aimed neither at improving our understanding of memory and other cognitive deficits associated with PD nor at enhancing functional recovery from such deficits. As far as cognitive functions are concerned, such studies merely noted that the surgical procedure did not induce permanent neuropsychological deficits (Leroy et al., 1996) and failed to arrest cognitive dysfunction permanently (Sass et al., 1995; Defer et al., 1996). Generally, these studies considered as implausible that normal cognitive function can be restored by dopaminergic-rich tissue transplantation because the cognitive impairments associated with PD do not appear to originate solely from dopamine deficiency. If one is interested in the impact of neural transplantation on memory dysfunction, then one must quit human clinical studies and switch to animal models.

In animals with various memory deficits, intracerebral transplantation studies have been conducted to restore normal or close-to-normal memory function. Such deficits may be observed in aged animals, but have generally been produced experimentally by different methods of damaging the brain, mainly by mechanical (aspiration or transection), electrolytic, excitotoxic, or immunotoxic lesions of forebrain cholinergic projection systems. Memory deficits have also been produced by (a) lesions of the granule cells of the dentate gyrus; (b) transient, ischemia-producing focal damage, especially to the CA1 pyramidal cells of the dorsal hippocampus; or (c) chronic alcohol consumption, thereby producing signs of noradrenergic and cholinergic deafferentation in the hippocampus and neocortex (for reviews see Dunnett, 1991; Sinden et al., 1995). Now, the interpretation of lesion data raises some well-known problems that are linked to, for instance,

a) secondary degeneration in areas that are remote from the primary lesioned area,

b) degeneration of fibers of passage that run through the lesion area, or

c) reactive plastic processes that may underlie restorative or deleterious effects.

To circumvent this difficulty, it may be helpful to use several different approaches and to confront the findings. Intracerebral transplantation is one such approach, allowing the investigator to control certain factors involved and, possibly, to reach causal conclusions.

\section{ASSESSMENT OF THE CHOLINERGIC HYPOTHESIS OF COGNITIVE DYSFUNCTION BY INTRACEREBRAL TRANSPLANTS AND PHARMACOLOGY}

Most intracerebral transplantation studies that have been carried out in animals with the goal of improving recovery of cognitive functions were based on the cholinergic hypothesis of memory dysfunction (for example, Bartus et al., 1982, 1983, 1985; Collerton, 1986). Nearly all such studies were concerned with functional recovery after damage to one or to both of the two main cholinergic forebrain projection systems, namely the septo-hippocampal and the basalo-cortical systems.

The very first studies to address the question of transplant effects on cognitive functions were those by Dunnett, Low and colleagues in 1982 (Dunnett et al., 1982b; Low et al., 1982). Somewhat paradoxically, in terms of the histochemical and neurochemical effects of the grafts, the results of these studies were encouraging, but in terms of behavioral recovery in lesioned rats, the results were somewhat disappointing. The lesion paradigm consisted of bilateral aspiration of the fimbriafornix, a technique transecting virtually all dorsal hippocampal afferents and efferents, as well as commissural fibers.

The studies mentioned above assessed the behavioral effects of fimbria-fornix lesions and 
grafts of septal tissue (rich in cholinergic neurons) in a rewarded alternation task that is known to be sensitive to disruption of the hippocampal formation. Whereas the control rats were able to learn this task rapidly, the performance of rats with lesions remained at chance level. But nevertheless, the lesioned rats with cholinergic-rich septal transplants (intracavitary solid grafts or intrahippocampal suspension grafts), but not those with noradrenergic-rich and cholinergic-poor locus coeruleus transplants, showed a progressive improvement of their performances over the 8 weeks of testing. Like all other groups of rats with lesions, those with cholinergic-rich septal transplants failed to perform above chance level $(50 \%)$ during the initial test sessions, but eventually acquired the task to a $\mathbf{9 0 \%}$ performance level by the 8 th week. At this stage, those with cholinergic-rich septal transplants no longer differed from control rats in their asymptotic performance. Behavioral recovery appeared to be specific to the learning task used because the grafts did not attenuate the lesioninduced disturbances in spontaneous activity or in spontaneous alternation. Recovery appeared to depend also upon cholinergic hippocampal reinnervation because (a) recovery correlated significantly with acetyl-cholinesterase (AChE)positive fiber ingrowth from the grafts into the denervated host hippocampus, and (b) the locus coeruleus grafts did not reverse the lesioninduced impairments.

In a second study, Low and collaborators (1982) investigated the radial-maze performance of rats having virtually the same lesions as those in the first study, but with intracavitary solid fetal grafts from the septal region alone. Perhaps because of the greater difficulty of the radialmaze task, the rats with acetylcholine (ACh)-rich grafts showed no amelioration of their performances in this task, except when they were treated with the AChE inhibitor, physostigmine. One may assume that this pharmacological treatment allowed the host brain to use more efficiently the low quantities of $\mathrm{ACh}$ released by the grafted neurons, due to the prolonged synaptic availability of the neurotransmitter. Using a Morris watermaze task, Segal and collaborators (1989) reported similar findings in rats with electrolytic lesions of the medial septum or knife-cut lesions of the fimbria-fornix pathways, followed by intrahippocampal grafts of minced septal tissue. Graftinduced improvement of performance was found only under physostigmine treatment.

Although some of these early investigations provided somewhat disappointing results suggesting that grafts alone (without additional pharmacological treatment) may remain inefficient, the studies clearly demonstrated the potential efficacy of intracerebral transplants for supporting the recovery of cognitive functions after damage to the septo-hippocampal pathways. These and several later studies (for review, see Cassel et al., 1997) also highlighted the critical role played by cholinergic neurotransmission in the expression of such functions, whether involved in the processing of spatial information or in the control of non-spatial perseverative tendencies (for example, Dunnett et al., 1989).

By showing that atropine abolished the recovered water-maze place navigation in rats with septal suspension or solid grafts, Nilsson and coworkers (1987) corroborated that graftinduced recovery is dependent upon cholinergic replacement (see also Segal et al., 1989; Hodges et al., 1990; Li et al., 1992). Furthermore, experiments were conducted in marmosets, whose brain is structurally more closely related to the human than to the rat brain. The marmosets underwent either surgical transection of the fornix or excitotoxic lesions of the nucleus basalis magnocellularis (NBM). In discrimination learning, as assessed by the relatively complex tasks designed for the Wisconsin General Test Apparatus, only the ACh-rich grafts were shown to attenuate the lesion-induced deficits (for example, Ridley et al., 1994).

In collaboration with the groups of Harlow (UK), Lund (Sweden), and with our group, 
Dunnett (Dunnett et al., 1985) then investigated the function of the other main cholinergic forebrain projection system, namely the basalocortical system. In this study, rats sustained unilateral excitotoxic lesions of the NBM. Their learning, retention, and sensorimotor performances were compared with those of intact control rats and with those of rats with lesions given ectopic (cortically-placed) suspension grafts, either of cholinergic-rich embryonic ventral forebrain cells or of control cells taken from the embryonic hippocampus, which is virtually devoid of cholinergic neurons. NBM lesions led to acquisition and retention impairments in a multiple-trial passive avoidance task and in a water-maze task, as well as to locomotor hyperactivity, which is attributable to a reduction in within-trial habituation. Before being tested for retention of passive avoidance, each animal was given repeated training trials until it reached a uniform acquisition criterion of not entering that compartment within 300 seconds. Five days after reaching this criterion, the animal was tested for retention. Ventral forebrain grafts, but not control hippocampal grafts, attenuated the deficits of passive avoidance retention and of water-mazeaccuracy almost to the level of that in intact control rats, but had no effect on the acquisition impairments in either task nor on the habituation deficit in locomotor activity.

Altogether, the results of the marmoset study and those of several others (for review, see Dunnett, 1990, 1991; Sinden et al., 1995; Cassel et al., 1997) support the hypothesis of Bartus and collaborators (Bartus et al., 1982, 1983, 1985) that basal forebrain cholinergic systems contribute to certain memory processes, although one should keep in mind that different populations of cholinergic neurons do not show the same potential for survival, growth, and reinnervation after transplantation (Lewis \& Cotman, 1983; Gibbs et al., 1986; Heuschling et al., 1988; Nilsson et al., 1988; Clarke et al., 1990) suggesting that "neuronal properties beyond the transmitter are essential for the optimal performance of implanted neurons in intracerebral grafting experiments" (Nilsson et al., 1988; p. 204).

Neither the so-called septo-hippocampal nor the basalo-cortical pathways are exclusively cholinergic, however, these pathways contain noradrenergic, serotonergic, GABAergic, glutamatergic, and other fibers. Similarly, the grafts used in the previously mentioned studies were not exclusively cholinergic, but rather either rich in cholinergic neurons or virtually devoid of such neurons. Because another category of neurons may have co-varied with the cholinergic neurons and may actually have been at the origin of the reported effects, the idea that regional $\mathrm{ACh}$ is causally required for normal memory function remained to be proven.

Using gene transfer technology, Winkler and coworkers (1995) recently demonstrated that ACh is causally implicated in the reported effects and causally required for learning and memory. In that study, rats with bilateral excitotoxic lesions of the NBM received transplants of either primary fibroblasts that were genetically modified to express either Drosophila choline acetyltransferase (dChAT fibroblasts) or control fibroblasts. The fibroblasts were grafted into the frontal and parietal cortices, which are the main target areas of the cholinergic projections stemming from the NBM. The dChAT fibroblasts showed high levels of ChAT activity, producing and releasing $\mathrm{ACh}$, whereas the control fibroblasts neither expressed ChAT nor synthesized ACh. Whereas NBM lesions induced a permanent and selective impairment of learning and memory, as assessed by spatial navigation in the Morris water maze, grafts that enhanced neocortical ACh levels also improved learning and memory performances in that task. One may thus assume not only that $\mathrm{ACh}$ is necessary for learning and memory but also that its replacement within the neocortex is sufficient to attenuate learning and memory deficits after damage to the NBM.

All data presented thus far confirm the cholinergic hypothesis of cognitive (dys)function, 
particularly as long as spatial memory is concerned. Nevertheless, this conclusion needs qualification.

\section{THE ROLE OF SOME NONCHOLINERGIC NEUROTRANSMITTER SYSTEMS IN MEMORY DYSFUNCTION}

Because noradrenergic and central cholinergic neurons are plausibly dependent for their development, maintenance, and regrowth upon the same neurotrophin, namely nerve growth factor (NGF) (for example, Hefti et al., 1985; Hefti \& Will, 1987), cholinergic changes in the forebrain are accompanied by correlative changes in the noradrenergic system (for example, Milner \& Loy, 1980; Loy \& Moore, 1977; Madison \& Davis, 1983; Gasser \& Dravid, 1987). Cholinergic deafferentation of the hippocampus or the fronto-parietal cortex induces noradrenergic sprouting. In the hippocampus, sympathetic (noradrenergic) fibers invade the dentate gyrus and the CA3-CA4 region, inducing an increase of noradrenaline (NA) concentration in these areas (Madison \& Davis, 1983), reaching $>200 \%$ of normal at three months after lesion surgery. In addition, we have shown that cholinergic-rich grafts, implanted in the dorsal hippocampus, not only increase ChAT activity in this structure but also prevent the lasting increase of hippocampal NA concentration that is induced by septohippocampal damage (Cassel et al., 1992a). Therefore, NA could actually be the important factor for explaining the observed effects of both lesions and transplants.

An experiment conducted by our group (Bratt et al., 1995), however, led to the conclusion that the sympathetic sprouting induced by fimbriafornix lesions has no effect on the behavioral deficits induced by such lesions: Indeed, the deficits were the same whether the animals sustained or did not sustain superior cervical ganglionectomy at the same time as the fimbriafornix lesions. This conclusion might need some qualification, however, as sympathetic sprouting was shown to alter

a) retention in a passive avoidance task (Ayyagari et al., 1991);

b) maintenance behavior (Harrell et al., 1987); and

c) (but only in male rats) reacquisition in a radialmaze task (Harrell \& Parsons, 1988).

In the latter task, sympathetic sprouting had beneficial effects in female rats. It is noteworthy that these deficits were found at rather short postoperative delays (from a few days to a few weeks).

If the delivery of $\mathrm{ACh}$ into the denervated area is essential and, under some conditions, even sufficient for attenuating learning and memory deficits that are induced by damage to basal forebrain cholinergic nuclei, the literature also shows that this neurotransmitter alone seems insufficient for allowing or producing complete recovery of these functions in animals with cholinergic dysfunction (for example, Dunnett, 1991). For this reason, our group, as well as others, have tried to develop complementary therapeutic strategies, for instance by

a) enriching the postoperative housing conditions of grafted animals (Kelche et al., 1988, 1995);

b) combining intracerebral grafting with the administration of trophic factors (Kelche et al., 1996; Roeser et al., 1997); or

c) co-grafting several categories of fetal neurons, replacing some or all of those that have been damaged by the lesion (Jeltsch et al., 1994).

Our assumption was that, for inducing complete recovery after fimbria-fornix disruption, co-grafting fetal cholinergic neurons along with other kinds of fetal neurons may be more efficient than grafting either cellular category alone.

It is actually not surprising that recovery after cholinergic transplantation into the rostrally deafferented hippocampus is only partial because typically, the fimbria-fornix or septal lesions deafferent the hippocampus of several other subcortical connections besides the cholinergic ones. As a matter of fact, this explanation has 
recently received some support from the study by Leanza and coworkers (1998), who showed that in rats with selective cholinergic immunolesions, fetal cholinergic grafts (but not control grafts of cerebellar tissue) completely reversed the acquisition deficit in the water-maze place navigation task and thus fostered recovery to an extent greatly exceeding that previously seen in animals with non-selective lesions. In a shortterm memory task, however, the lesion-induced impairment was only partially and inconsistently affected by the cholinergic grafts.

When grafted alone into the hippocampus, transplants rich in noradrenergic or serotonergic neurons have no influence on the cognitive performances of the animals (Dunnett et al., 1982a; Nilsson et al., 1990; but see RichterLevin et al., 1993). By contrast, co-grafts of cholinergic-rich and serotonergic-rich tissues were shown to be more effective than cholinergic-rich grafts alone (Jeltsch et al., 1994; Nilsson et al., 1990). Indeed, accumulating evidence has suggested that serotonin (5-HT) may modulate cholinergic function in several regions of the mammalian brain and that such serotonergic/cholinergic interactions may influence some aspects of cognition (for example, Richter-Levin \& Segal, 1989; Cassel \& Jeltsch, 1995; Steckler \& Sahgal, 1995). For increasing the therapeutic efficacy of intracerebral transplantation and for studying further $\mathrm{ACh} / 5-\mathrm{HT}$ interactions by using intracerebral transplants, we carried out a series of experiments on co-grafting cholinergic-rich and serotonergic-rich neuronal populations.

Our neurochemical data showed that after extensive denervation of the hippocampus by aspirative lesions of the fimbria-fornix and overlying structures, intrahippocampal grafts of fetal neurons fostered a neurotransmitter-specific recovery that depended on the anatomical origin of the grafted cells. Indeed, we have shown that grafts rich in serotonergic neurons compensated or even overcompensated for the 5-HT deficit (for example, 5-HT uptake by hippocampal synaptosomes reached $324 \%$ of the values found in sham-operated rats), and grafts rich in cholinergic neurons attenuated the cholinergic deficit, whereas combining both 5-HT-rich and ACh-rich transplants produced recovery, close to normal, from both deficits (Cassel et al., 1992b, 1993).

In the Morris water maze and without any additional pharmacological treatment, rats with electrolytic fimbria-fornix lesions remained impaired when they received only septal or raphe grafts (Jeltsch et al., 1994). With combined cholinergicrich and serotonin-rich grafts, however, the rats showed virtually complete recovery in the probe trial of this task, whether one considers the distance swum or the time spent by the co-grafted rats in the training quadrant (where the platform was located during the acquisition trials). This result is all the more noteworthy because the co-grafts contained only about one-half the number of cells of each category, when compared with the corresponding single grafts.

In the radial-maze task, the same co-grafted rats, as well as those receiving separate grafts, showed no significant improvement of performance. This observation suggests that the two behavioral tasks, aimed at measuring spatial memory and orientation capacities, do not assess exactly the same functions (see Hodges, 1996). For instance, in a radial maze, animals may solve the task without calling on any cognitive mapping capacity: They may use proximal sensory cues or orientation strategies that are based on regular sequences of angular turns. In contrast, in the water maze, the possibility of using proximal cues and orientation strategies remains utterly limited. Thus, even cholinergic/serotonergic-rich co-grafts cause only partial recovery from lesion-induced navigation deficits. As the radial-maze task placed emphasis on spatial working memory and the water-maze task used by Jeltsch et al. (1994) placed emphasis on reference memory, one may also speculate that cholinergic and serotonergic innervation of the hippocampus preferentially ameliorates spatial reference memory. Recently, we have obtained some results in favor of such a 
possibility (Balse et al., 1999). An alternative but not necessarily exclusive hypothesis may be based on a recent article by Leanza et al., 1998), who showed that complete reinnervation of cortical and hippocampal territories, selectively deprived of their cholinergic innervation, contributes toward normalizing or to improving only some aspects of cognitive deficits, particularly those that are related to reference memory. Conversely, shortterm memory capabilities are only inconsistently affected. The authors attribute this limited capacity of the grafts to insufficient integration into the host circuitry because of their ectopic placement (septal cells in the hippocampus). Although our study (Balse et al., 1999) differed in several methodological respects from that of Leanza and coworkers (1998), it cannot be ruled out that a comparable explanation may apply to the fact that our grafts affected mainly long-term memory.

Nevertheless, when taken together, the results mentioned previously support the idea that the cholinergic neurotransmission system has an essential, though not exclusive, part in the expression of cognitive functions, such as spatial memory. As shown by Dunnett and coworkers (Dunnett et al., 1985) in their study on stepthrough passive avoidance, this conclusion may also apply to other non spatial forms of memory.

The cholinergic, as well as the serotonergic, terminals within the hippocampus and cortex are located far from their cell bodies, and the graftderived axons may be considered unable to reach their target areas if the grafts are homotopically implanted. For both reasons, all previous studies have used heterotopic transplantation as suspension grafts in the target parenchyma or, more rarely, as solid grafts implanted into a lesion cavity in direct contact with the target structure (for review, see Cassel, et al., 1997). Because such ectopic grafts were able to cause behavioral recovery, it appears unnecessary for the neurotransmitter activity of the grafted neurons to be regulated as finely as it may be in the septo-hippocampal or the basalo-cortical systems of an intact brain.

\section{THE NECESSITY FOR CIRCUITRY REPAIR ASSESSED BY ECTOPIC AND HOMOTROPIC TRANSPLANTS}

The assumption that homotopic grafts would turn out to be ineffective for compensating the loss of long-distance projection neurons has actually received experimental support. Hodges and her colleagues (1991) checked whether grafts that are implanted in homotopic position are as efficient as those implanted into target areas for inducing functional recovery. The investigators used rats with ibotenate lesions of both NBM and medial septum that showed a long lasting impairment in both reference and working memory, as assessed in a radial-maze task. Cell suspension grafts of cholinergic-rich fetal basal forebrain tissue, whether located in the cortex, in the hippocampus, or in both regions of the host brain, substantially improved cognitive performance. In contrast, no amelioration of cognitive deficits was observed in rats with cholinergic-rich transplants that were homotopically located in the basal forebrain.

In addition, Hodges and her colleagues (1991) added an important control situation to their experiment to assess whether the rats actually used distal cues for mastering the task. Like the control animals, rats with behaviorally effective grafts were disrupted in the place version of the task when tested in dim light. In contrast, lesioned rats, as well as rats with noncholinergic grafts, were not affected by the modification of the lighting conditions. So, as rats with heterotopic cholinergic-rich grafts showed both a reduced number of errors and recovery of stimulus control, one may assume that these grafts affected information processing, rather than changes in motor or motivational processes.

Functional recovery may involve local, nonspecific synaptic or paracrine mechanisms within target regions because the grafts were efficacious only when placed in terminal areas, but not when located homotopically, in the basal forebrain. 
This finding suggests that the grafting did not achieve any functionally significant structural repair to the host brain at that site. The last conclusion, however, requires some qualification, as homotopic implantation in the lesion area may prove efficacious when the damaged neurons are not long-distance projection neurons, but rather neurons involved in local circuits, such as CA1 pyramidal neurons or dentate granule cells. Indeed, the group of Gray (Hodges et al., 1994; Netto et al., 1993a; 1993b; Nunn \& Hodges, 1994) showed that rats with both CA1 lesions induced by transitory global cerebral ischemia and CA1 cells grafted homotopically into the CA1 area manifested a virtually complete behavioral recovery when tested for water-maze learning/memory performance. The recovery was observed not only in a learning task to orient in a novel pool but also in a retention test of a familiar pool, in a reversal learning of the original platform position, and in a working memory task. In contrast, neither CA3 grafts nor dentate gyrus (DG) grafts produced any positive effect on the spatial capability of the CA1lesioned rats. The effects of CA1 grafts in restoring spatial abilities suggest that these grafts may have assisted with repair to the damaged host circuit rather than having acted through the release of an appropriate neurotransmitter because the DG grafts, although glutamatergic, were ineffective for mending ischemia-induced deficits. In a further set of experiments, in which the granule cells of the DG were selectively damaged by local injection of colchicine, the same group compared the efficacy of DG and CA1 grafts that were placed into the lesioned dorsal hippocampus. At 8 weeks after transplantation surgery, the rats with DG, but not those with CA1, grafts showed an improvement in the water-maze acquisition relative to lesioned, non-grafted rats (Xavier et al. In: Sinden et al., 1995, p. 29).

In other respects, in rats with fimbria-fornix lesions, ectopic cholinergic-rich grafts do not significantly attenuate lesion-induced, noncognitive disturbances, such as locomotor hyper-activity (for example, Dunnett et al., 1982b; but see Cassel et al., 1992b). Fimbria-fornix lesions also abolish rhythmic slow activity (RSA or theta) in the hippocampus, and no recovery is seen in either control-lesioned rats or in rats with nonseptal suspension grafts (Buzsaki et al., 1987; 1992). Recovery of RSA was observed in rats with solid septal grafts, however, and in some rats with solid hippocampal grafts implanted into the fimbria-fornix lesion cavity. As in normal rats, RSA was present only during running and absent during drinking and sitting still. In contrast to the rats with solid grafts, those with hippocampal septal suspension grafts displayed only short duration bursts of RSA, and those mainly during immobility. The findings suggest that at least some of the RSA pacemaker cells of the host septum survive the fimbria-fornix transection, and that solid grafts implanted into the lesion cavity may be capable of relaying this pacemaker activity to the host hippocampus.

Circuitry repair that may be achieved by various means (for the septo-hippocampal system, see for example, Kromer et al., 1981; for review see Will et al., 1998) thus seems necessary for the recovery of certain functions, such as hippocampal RSA, because the link between the septum and the hippocampus is required for the transfer of information from the RSA pacemaker cells, located in the septum, to the hippocampus. Circuitry repair, however, seems unnecessary for certain other functions, the recovery of which can be achieved solely by restoring within a deafferented area a paracrine level of various neurotransmitters, without any necessity for rebuilding a point-to-point circuitry. Thus, from a therapeutic viewpoint, alleviating all kinds of symptoms after brain injury is obviously a goal that may be reached, in some cases, only by combining different strategies:

a) rebuilding the circuitry for correcting certain deficits (such as locomotor hyperactivity and suppression of hippocampal RSA), and 
b) furnishing sufficient amounts of the defective molecules in situ for ameliorating other rather general (perhaps attentional) functions.

This is precisely the goal that Duconseille and co-workers (Hofferer-Duconseille, 1997a; 1997b; Duconseille et al., 1999) tried to reach by combining, in a recent series of experiments, polymeric hydrogel implantation with homotopic fetal cell transplantation

According to Ramon Y. Cajal (1928):

Once development is completed, the sources of growth and regeneration of axons and dendrites are irrevocably lost.

In the adult brain, nervous pathways are fixed and immutable; everything may die, nothing may be regenerated.

By adopting such a view, the 1906 Nobel prize laureate most likely contributed to the general acceptance of the idea that axons are unable to regrow after injury within the adult mammalian central nervous system (CNS). Today, however, we do know that this assertion needs serious qualification because we now recognize that even in the adult mammalian CNS, neurons have an endogenous ability to regenerate after injury; the expression of their intrinsic ability to do so requires the appropriate micro-environmental conditions (for example, Will et al., 1998).

Among the several possibilities that may create such conditions (for example, Kromer \& Cornbrooks, 1987; Messersmith et al., 1991; Neuberger et al., 1992), Duconseille and coworkers (1998) chose to use unmodified or amino-sugar-containing biocompatible polymeric hydrogels furnished by Dr. Woerly (Organogel Canada Ltée). These polymers were assumed to provide regrowing or growing neuronal fibres with an artificial growth-promoting substrate mimicking some aspects of the extracellular matrix found in the lower vertebrate CNS, the mammalian developing CNS, or the peripheral nervous system, three systems that show spontaneous regeneration (for example, Will et al., 1998). Hydrogels are hydrophilic, polymerbased macromolecular networks that are swollen in water. Their permeability to small molecules, the micro-geometry of their porous network, and the size of their pores are key characteristics concerning their chances to allow damaged neurons to regenerate their axons within the three-dimensional organization of the hydrogel (for example, Woerly et al., 1995; 1996; 1998). Duconseille and coworkers (Duconseille et al., 1998) used (2-hydroxypropyl)methacrylamide (HPMA) hydrogels, which among all hydrogels tested-according to Woerly and coworkers (1993) - show the highest adhesion properties with living cells. The first experiment evaluated the potential of the hydrogel matrix to support glial cell infiltration, angiogenesis, and axonal regeneration when the gel is implanted into the adult rat brain to close an $\sim 2.5 \mathrm{~mm}$ gap, created by an aspirative lesion of the fimbria-fornix pathways. Six months after lesion surgery, all the hydrogels were found to be well integrated into the brain, adhering to host brain tissue and making up a stable bridge between the septum and the hippocampus. The hydrogels contained blood vessels and were invaded by host cells, including astrocytes. Fiber penetration was most important in the $\mathrm{N}$-acetylglucosamine-containing hydrogels. Despite these features, the hippocampus failed to show any significant increase of AChE-staining, as compared with that seen in the lesion-only rats. The results of this experiment confirmed the regeneration capacity of severed septo-hippocampal neurons into a polymeric substrate; the results also showed the limitation of this process, which, at least as far as cholinergic neurons are concerned, remained limited to the hydrogel and failed to reinnervate the hippocampus.

Because fetal neurons have a higher neuritic growth potential than adult neurons do and exhibit a high survival rate after intracerebral implantation, intraseptal homotopic fetal cell grafts were combined, in certain complementary experiments, with an intracavitary hydrogel 
implantation (Hofferer-Duconseille, 1997; Will et al., 1998; Duconseille et al., 1997a, 1997b, 1999). This approach was assumed to allow a growth of axons across the "bridge" that is more powerful than the growth of severed adult septal axons that was seen in the previous experiment. The double implantation (hydrogel + fetal cells) induced a cholinergic reinnervation of the anterior pole of the hippocampus, reaching a distance farther than $300 \mu \mathrm{m}$ from the polymer/ hippocampus interface. Double implantation also induced a partial recovery of certain electrophysiological characteristics of hippocampal function: In rats with a double implantation, Duconseille and coworkers (1999) observed a partial restoration of the correlation between the instantaneous velocity of the rat and the firing rate of the hippocampal interneurons, also named "theta" cells; between the head direction of the rat and the firing rate of place cells; and of the rhythmic modulation of the cellular activity of both kinds of cells. The double implantation, however, had no effect on the lesion-induced perturbations of some functional characteristics of place cells. Finally and most important, double implantation significantly attenuated lesioninduced locomotor hyperactivity, but did not alleviate lesion-induced reference and working memory deficits as assessed in water-maze and radial-maze tasks.

\section{CONCLUSION}

One knows that cholinergic-rich grafts or both cholinergic- and serotonergic-rich co-grafts, heterotopically implanted into the hippocampus, may normalize mnemonic function, or at least attenuate mnemonic dysfunction. Such grafts, however, produce mnemonic improvements without reducing locomotor hyperactivity and restoring the rhythmic modulation of activity in hippocampal neurons. It is therefore tempting to confront the contrasting outcomes of such heterotopic transplantations and of homotopic grafts combined with an artificial "bridge" implantation. In particular, one may assume that a more extensive reinnervation of the hippocampus following regrowth through the polymer (or another kind of) bridge could be achieved by using appropriate growth promoting and guiding factors and/or by antagonizing growth inhibiting factors (for example, Will et al., 1998). If the achieved reinnervation is similar to that observed following heterotopic transplantation, it would be tempting to assume that the double implantation (homotopic fetal cell transplants + polymer "bridge") could entail a combination of the effects that are observed after heterotopic and after homotopic + bridge grafts. The effects may be simply additive, which would in any event constitute a serious progress in comparison with the separate outcomes of either heterotopic or homotopic grafts; nonetheless, such effects may even be interactive, one kind of graft potentiating the effects of the other. The latter possibility seems plausible because the reinstatement of normal or close-to-normal RSA and of normal locomotor activity may favor normal cognitive performance (for example, Wetzel et al., 1977; Mayeux \& Stern, 1983; Growdon et al., 1990; Vinogradova, 1995).

Apart from the advantage of intracerebral grafts as a potent experimental tool in basic neurobiological research, the clinical applicability of intracerebral grafts for alleviating memory disturbances in aged individuals or for treating the dementia of patients with Alzheimer's disease remains, as stated by Dunnett (1991) and by Lindvall (1991), quite limited and premature, at least in a foreseeable future. Indeed, the moderate forgetfulness that is observed in aged individuals does not justify intracerebral transplantation, which would constitute too heavy a surgical intervention applicable to too many people. In patients with Alzheimer's disease, the cognitive deficits are too severe and the neuropathological changes too widespread for considering a topical neurosurgical intervention as an adapted means for 
producing a wide-ranging structural and functional repair. Therefore, a therapeutic approach relying more specifically upon pharmacological treatments should be more appropriate.

Nevertheless, some other dementiae exist, originating apparently from a more restricted degeneration of subcortical cholinergic neurons and leaving their cortical targets relatively intact. Such a case has been made for the dementia observed in a subpopulation of patients with Parkinson's disease, which is characterized by a high number of Lewy bodies colonizing their basal forebrain nuclei (Candy et al., 1983;
Whitehouse et al, 1983; but also see Mayeux et al., 1983). The treatment of this pathology by intracerebral transplants might deserve particular attention.

\section{ACKNOWLEDGEMENTS}

This work was supported by the D.R.E.T. (grant 93-086, France) and by a NATO Collaborative Research Grant (CRG 950247). The authors thank Dr. Hélène Jeltsch for her invaluable comments regarding the manuscript.

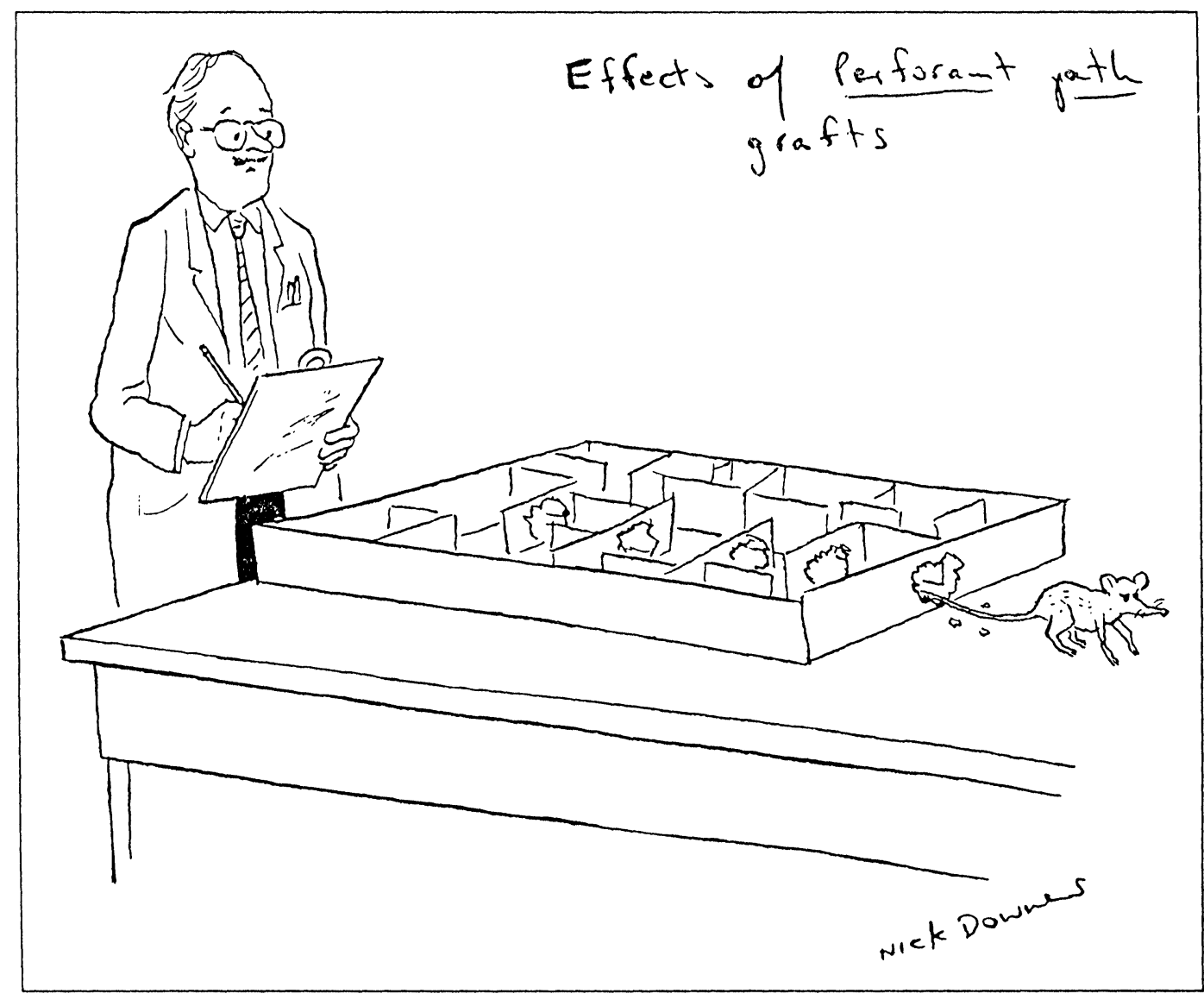

Annotation by Simon Brailowsky, written in his own hand. 


\section{REFERENCES}

Ayyagari V, Harrell LE, Parsons DS. Interaction of neurotransmitter systems in the hippocampus: a study of some behavioral effects of hippocampal sympathetic ingrowth. J Neurosci 1991; 11: 2848-2854.

Balse E, Lazarus C, Kelche C, Jeltsch H, Jackisch R, Cassel JC. Intrahippocampal grafts containing cholinergic and serotonergic fetal neurons ameliorate spatial reference but not working memory in rats with fimbria-fornix/ cingular bundle lesions. Brain Res Bull, 1999; in press.

Bartus RT, Dean RL, Beer B, Lippa AS. The cholinergic hypothesis of geriatric memory dysfunctions. Science 1982; 217: 408-417.

Bartus RT, Dean RL, Pontecorvo MJ, Flicker C. The cholinergic hypothesis: a historical overview, current perspective and future directions. In: Olton D, Gamzu E, Corkin S, eds, Memory Dysfunctions. NY Acad Sci, 1985.

Bartus RT, Flicker C, Dean RL. Logical principles for the development of animal models of agerelated memory impairments. In: Crook T, Ferris $\mathrm{S}$, Bartus RT, eds, Assessment in Geriatric Psychopharmacology. New Cannan, CT: Mark Powley, 1983; 263-299.

Bratt AM, Cassel JC, Neufang B, Greene PL, Jackisch R, Hertting $G$ et al. Behavioral and neurochemical effects of superior cervical ganglionectomy in rats with septo-hippocampal lesions: influences on spatial working memory. Exp Brain Res 1995; 102: 429-444.

Buzsaki G, Gage FH, Czopf J, Björklund A. Restoration of rhythmic slow activity (theta) in the subcortically denervated hippocampus by fetal CNS transplants. Brain Res 1987; 400: 334-347.

Buzsaki G, Hsu M, Horvath Z, Gage FH. Physiological and behavioral consequences of delayed septal grafts in the subcortically denervated hippocampus. Resto Neurol Neurosci 1992; 4: 369-380.

Candy JM, Perry RH, Perry EK, Erwing D, Blessed G, Fairbairn AF et al. Pathological changes in the nucleus of Meynert in Alzheimer's and Parkinson's disease. J Neurol Sci 1983; 54: 277-289.

Cassel JC, Duconseille E, Jeltsch H, Will B. The fimbria-fornix/cingular bundle pathways: a review of neurochemical and behavioral approaches using lesions and transplantation techniques. Prog. Neurobiol. 1997; 51: 663-716.
Cassel JC, Kelche C, Neufang B, Will B, Hertting G, Jackisch R. Graft-derived cholinergic reinnervation of the hippocampus prevents a lasting increase of hippocampal noradrenaline concentration induced by septo-hippocampal damage in rats. Neurosci Lett 1992a; 138: 32-36.

Cassel JC, Neufang B, Kelche C, Aiple F, Will B, Hertting $G$ et al. Effects of septal and/or raphe cell suspension grafts on hippocampal choline acetyl-transferase activity, high affinity synaptosomal uptake of choline and serotonin, and behavior in rats with extensive septohippocampal lesions. Brain Res 1992b; 585: 243-254.

Cassel JC, Neufang B, Kelche C, Jeltsch H, Will $B E$, Hertting $G$ et al. Effects of grafts containing cholinergic and/or serotonergic neurons on cholinergic, serotonergic and noradrenergic markers in the denervated rat hippocampus. Brain Res 1993; 604: 53-63.

Cassel JC, Jeltsch H. Serotonergic modulation of cholinergic function in the central nervous system: cognitive implications. Neurosci 1995; 69: $1-41$.

Clarke DJ, Nilsson OG, Brundin P, Björklund A. Synaptic connections formed by grafts of different types of cholinergic neurons in the host hippocampus. Exp Neurol 1990; 107: 11-22.

Collerton D. Cholinergic function and intellectual decline in Alzheimer's disease. Neurosci 1986; 19: 1-28.

Defer GL, Geny C, Ricolfi F, Fenelon G, Monfort $\mathrm{JC}$, Remy $\mathrm{Ph}$, et al. Long-term outcome of unilaterally transplanted parkinsonian patients. I. Clinical approach. Brain 1996; 119: 41-50.

Dubois B, Boller F, Pillon B, Agid Y. Cognitive deficits in Parkinson's disease. In: Boller F, Grafman J, eds, Handbook of Neuropsychology. Amsterdam: Elsevier Science Publishers 1991; 5: $195-240$.

Duconseille E, Cressant A, Kelche C, Woerly S, Will B, Poucet B et al., Homotopic septal grafts combined with a hydrogel bridge promote functional recovery in rats with fimbria-fornix lesions: a unit recording study. Restor Neurol Neurosci 1999; in press.

Duconseille E, Kelche C, Woerly S, Will B, Cassel JC. Polymeric hydrogel bridging a fimbriafornix lesion cavity combined to homotopic fetal septal cell suspension grafts in the rat: behavioral and morphological approaches. Sixth International Neural Transplantation Society Meeting, San Diego, 1997a. 
Duconseille E, Woerly S, Kelche C, Will B, Cassel JC. Morphological and behavioral study of septohippocampal regeneration after fimbria-fornix lesions in the rat with septal cell-suspension grafts and/or polymeric hydrogels as regenerating bridges. Sixth International Neural Transplantation Society Meeting, San Diego, $1997 \mathrm{~b}$.

Duconseille E, Woerly S, Kelche C, Will B, Cassel JC. Polymeric hydrogels placed into a fimbriafornix lesion cavity promote fiber (re)growth: a morphological study in the rat. Restor Neurol Neurosci 1998; 13: 193-204.

Dunnett SB. Neural transplantation in animals models of dementia. Eur J Neurosci 1990; 2: 567-587.

Dunnett SB. Cholinergic grafts, memory and ageing. Trends Neurosci 1991; 14: 371-376.

Dunnett SB, Gage FH, Bjorklund A, Stenevi U, Low WC, Iversen SD. Hippocampal deafferentation: transplant-derived reinnervation and functional recovery. Scan. J. Psychol. 1982a; 1: 104-111.

Dunnett SB, Low WC, Iversen SD, Stenevi U, Bjorklund A. Septal transplants restore maze learning in rats with fimbria-fornix lesions. Brain Res 1982b; 251: 335-348.

Dunnett SB, Martel FL, Rogers DC, Finger S. Factors affecting septal graft amelioration of differential reinforcement of low rates (DRL) and activity deficits after fimbria-fornix lesions. Restor Neurol Neurosci 1989; 1: 83-92.

Dunnett SB, Toniolo G, Fine A, Ryan CN, Björklund A, Iversen SD. Transplantation of embryonic ventral forebrain neurons to the neocortex of rats with lesions of nucleus basalis magnocellularis. II. Sensorimotor and learning impairments. Neurosci 1985; 16: 787-797.

Freed CR, Breeze RE, RosenbergNL, Schneck SA, Wells TH, Barrett $\mathrm{JN}$ et al. Transplantation of human fetal dopamine cells for Parkinson's disease. Arch Neurol 1990; 47: 505-512.

Freed CR, Breeze RE, Rosenberg NL, Schneck SA, Kriek E, Qi JX et al. Survival of implanted fetal dopamine cells and neurologic improvement 12 to 46 months after transplantation for Parkinson's disease. N Engl J Med 1992; 327: 1549-1555.

Gasser UE, Dravid AR. Noradrenergic, serotonergic, and cholinergic sprouting in the hippocampus that follows partial or complete transection of the septo-hippocampal pathway: contribution of spared inputs. Exp Neurol 1987; 96: 352-364.

Gibbs RB, Anderson K, Cotman CW. Factors affecting innervation in the CNS: comparison of three cholinergic cell types transplanted to the hippocampus of adult rats. Brain Res 1986;383: 362-366

Growdon JH, Corkin S, Rosen JT. Distinctive aspects of cognitive dysfunction in Parkinson's disease. In: Streifler M, ed, Parkinson's Disease. Advances in Neurobiology. New York: Raven Press 1990; 365-376.

Harrell LE, Parsons DS. Role of gender in the behavioral effects of peripheral sympathetic ingrowth. Exp Neurol 1988; 99: 315-325

Harrell LE, Parsons DS, Peagler A, Barlow TS. Alterations in regulatory behaviors induced by medial septal lesions and superior cervical ganglionectomy. Brain Res 1987; 408: 131-140.

Hefti F, Hartikka J, Eckenstein F, Gnahn H, Heumann R, Schwab M. Nerve growth factor (NGF) increases choline acetyltransferase but not survival or fiber growth of cultured septal cholinergic neurons. Neurosci 1985; 14: 55-68.

Hefti F, Will B. Nerve growth factor is a neurotrophic factor for forebrain cholinergic neurons; implications for Alzheimer's disease. J Neural Transm 1987; 24: 309-315.

Heuschling P, De Parmentier F, Van den Bosch de Aguilar P. Topographical distribution in the adult rat brain of neurotrophic activities directed to central nervous system targets. Dev Brain Res 1988; 38: 9-17.

Hitchcock ER, Clough C, Hughes R, Kenny B. Embryos and Parkinson's disease. Lancet 1988; 1: 1274.

Hodges $H$. Maze procedures: the radial-arm and water maze compared. Brain Res Cogn Brain Res 1996; 3: 167-181

Hodges H, Allen Y, Kershaw T, Lantos PL, Gray JA, Sinden J. Cholinergic-rich neural transplants alleviate cognitive deficits in lesioned rats but exacerbate response to cholinergic drugs. In: Dunnett SB and Richards SJ, eds, Neural Transplantation: From Molecular Basis to Clinical Application. Amsterdam: Elsevier 1990; 347-358.

Hodges H, Allen Y, Kershaw T, Lantos PL, Gray JA, Sinden J. Effects of cholinergic-rich neural grafts on radial maze performance of rats after excitotoxic lesions of the forebrain cholinergic projection system. I. Amelioration of cognitive deficits by transplants into cortex and hippocampus but not into basal forebrain. Neurosci 1991; 45: 587-607

Hodges H, Sinden J, Meldrum B, Gray J. Cerebral transplantation in animals models of ischemia. 
Funct Neural Transplant 1994; 2: 347-386.

Hofferer-Duconseille E. Restauration fonctionnelle après lésion massive des voies septohippocampiques chez le Rat: implantation conjointe de biomatériaux et de greffes homoopiques de neurones de projection. Doctoral dissertation, Université Louis Pasteur, 1997.

Jeltsch H, Cassel JC, Neufang B, Kelche C, Hertting $G$, Jackisch $R$ et al. The effects of intrahippocampal raphe and/or septal grafts in rats with fimbria-fornix lesions depend on the origin of the grafted tissue and the behavioral task used. Neurosci 1994; 63: 19-39

Kelche C, Roeser C, Schumm S, Will B. Ginkgo biloba (Egb 761) can promote some behavioral recovery after septo-hippocampal damage in the rat, but its effects depend upon the degree of hippocampal deafferentation. In: Christen Y, Droy-Lefaix MT, Macias-Nunez JF, eds, Advances in Ginkgo biloba Extract Research, vol. 5. Effects of Ginkgo biloba Extract (Egb 761) on Neuronal Plasticity. Paris: Elsevier 1996; 85-99.

Kelche C, Dalrymple-Alford JC, Will B. Housing conditions modulate the effects of intracerebral grafts in rats with brain lesions. Behav Brain Res 1988; 28: 287-295.

Kelche C, Roeser C, Jeltsch H, Cassel JC, Will B. The effects of intrahippocampal grafts, and postoperative housing on behavioral recovery after septo-hippocampal damage in the rat. Neurobiol Learn Mem 1995; 63: 155-166.

Kromer LF, Björklund A, Stenevi U. Regeneration of the septo-hippocampal pathways in adult rats is promoted by utilizing embryonic hippocampal implants as bridges. Brain Res 1981; 210: 173200.

Kromer LF, Cornbrooks CJ. Identification of trophic factors and transplanted cellular environments that promote CNS axonal regeneration. Ann N Y Acad Sci 1987; 495: 207-224.

Lavernhe G, Pollak P, Brenier F, Gaio JM, Hommel M, Pellat $\mathbf{J}$ et al. Maladie d'Alzheimer et maladie de Parkinson. Différenciation neuropsychologique. Rev Neurol (Paris) 1989; 145: 24-30.

Leanza G, Martinez-Serrano A, Björklund A. Amelioration of spatial navigation and shortterm memory deficits by grafts of fetal basal forebrain tissue placed into the hippocampus and cortex of rats with selective cholinergic lesions. Eur J Neurosci 1998; 10: 2353-2370.

Leroy A, Michelet D, Mahieux F, Geny C, Defer G, Monfort JC et al. Examen neuropsychologique de 5 patients parkinsoniens avant et après greffe neuronale. Rev Neurol 1996; 152: 158-164.

Lewis ER, Cotman CW. Neurotransmitter characteristics of brain grafts: striatal and septal tissues form the same laminated input to the hippocampus. Neuroscience 1983; 8: 57-66.

Li YJ, Simon JR, Low WC. Intrahippocampal grafts of cholinergic-rich striatal tissue ameliorate spatial memory deficits in rats with fimbriafornix lesions. Brain Res Bull 1992; 29: 147155.

Lindvall O, Rehncrona S, Gustavii B, Brundin P, Astedt B, Widner $\mathrm{H}$ et al. Fetal dopamine-rich mesencephalic grafts in Parkinson's disease. Lancet 1988 ; 2: 1483-1484.

Lindvall O, Rehncrona S, Brundin P, Gustavii B, Astedt B, Widner $\mathrm{H}$ et al. Human fetal dopamine neurons grafted into the striatum in two patients with severe Parkinson's disease. A detailed account of methodology and a 6-month follow-up. Arch Neurol 1989 ;46: 615-631

Lindvall $\mathrm{O}$, Brundin $\mathrm{P}$, Widner $\mathrm{H}$, Rehncrona $\mathrm{S}$, Gustavii B, Frackowiak R et al. Grafts of fetal dopamine neurons survive and improve motor function in Parkinson's disease. Science 1990; 247: 574-577.

Lindvall $O$. Prospects of transplantation in human neurodegenerative diseases. Trends Neurosci 1991; 14: 376-384

Low WC, Lewis RR, Bunch ST, Dunnett SB, Thomas SR Iversen SD, et al. Functional recovery following neural transplantation of embryonic septal nuclei in adult rats with septohippocampal lesions. Nature 1982; 300: 260-262.

Loy R, Moore RY. Anomalous innervation of the hippocampal formation by peripheral sympathetic axons following mechanical injury. Exp Neurol 1977; 57: 645-650.

Madison R, Davis JN. Sprouting of noradrenergic fibers in hippocampus after medial septal lesions: contributions of the central and peripheral nervous system. Exp Neurol 1983; 80: $167-177$.

Madrazo I, Franco-Bourland R, Ostrosky-Solis F, Aguilera M, Cuevas C, Zamorano C et al. Fetal homotransplants (ventral mesencephalon and adrenal tissue) to the striatum of Parkinsonian subjects. Arch Neurol 1990; 47: 1281-1285.

Madrazo I, Leon V, Torres C, Aguilera MC, Varela G, Alvarez $F$ et al. Transplantation of fetal substantia nigra and adrenal medulla to the caudate nucleus in two patients with Parkinson's disease. N Engl J Med 1988; 318: 51. 
Mayeux R, Stern Y. Intellectual dysfunction and dementia in Parkinson's disease. In: Mayeux R, Rosen WG, eds, The Dementias. New York: Raven Press, 1983; 211-227.

Mayeux R, Stern Y, Rosen J, Benson F. Is "subcortical dementia" a recognizable clinical entity? Ann Neurol 1983; 14: 278-283.

Messersmith DJ, Fabrazzo M, Mocchetti I, Kromer LF. Effects of sciatic nerve transplants after fimbriafornix lesion. Examination of the role of nerve growth factor. Brain Res 1991; 557: 293-297.

Milner TA, Loy R. A delayed sprouting response to partial hippocampal deafferentation: time course of sympathetic ingrowth following fimbria lesions. Brain Res 1980; 197: 391-399.

Netto CA, Hodges H, Sinden JD, Le Peillet E, Kershaw T, Sowinski $P$ et al. Effects of fetal hippocampal field grafts on ischaemic-induced deficits in spatial navigation in the water maze. Neurosci 1993a; 54: 69-92.

Netto CA, Hodges $H$, Sinden JD, LePeillet E, Kershaw T, Sowinski $P$ et al. Fetal grafts from hippocampal regio superior alleviate ischaemicinduced behavioral deficits. Behav Brain Res 1993b; 58: 107-112.

Neuberger TJ, Cornbrooks CJ, Kromer LF. Effects of delayed transplantation of cultured Schwann cells on axonal regeneration from central nervous system cholinergic neurons. J Comp Neurol 1992; 315: 16-33.

Nilsson OG, Brundin P, Björklund A. Amelioration of spatial memory impairment by intrahippocampal grafts of mixed septal and raphe tissue in rats with combined cholinergic and serotonergic denervation of the forebrain. Brain Res 1990; 515: 193-206.

Nilsson OG, Clarke DJ, Brundin P, Björklund A. Comparison of growth and reinnervation properties of cholinergic neurons from different brain regions grafted to the hippocampus. J Comp Neurol 1988; 268: 204-222.

Nilsson OG, Shapiro ML, Gage FH, Olton DS, Bjöklund A. Spatial learning and memory following fimbria-fornix transection and grafting of fetal septal neurons to the hippocampus. Exp Brain Res 1987; 67: 195-215.

Nunn J, Hodges $H$. Cognitive deficits induced by global cerebral ischemia: relationship to brain damage and reversal by transplants. Behav Brain Res 1994; 65: 1-31.

Peschanski M, Defer G, N'Guyen JP, Ricolfi F, Monfort JC, Remy $P$ et al. Bilateral motor improvement and alteration of L-dopa effect in two patients with Parkinson's disease following intrastriatal transplantation of fetal ventral mesencephalon. Brain 1994; 117: 487-499

Ramon Y, Cajal S. In: May RM, ed, Degeneration and Regeneration in the Nervous System. New York: Hafner 1928, 1959.

Richter-Levin G, Greenberger V, Segal M. Regional specificity of raphe graft-induced recovery of behavioral functions impaired by combined serotonergic/cholinergic lesions. Expl Neurol 1993; 121: 256-260.

Richter-Levin G, Segal M. Raphe cells grafted into the hippocampus can ameliorate spatial memory deficits in rats with combined serotonergic/ cholinergic deficiencies. Brain Res 1989; 478: 184-186.

Ridley RM, Baker HF, Annett LE, Dunnett SB, Torres EM, Fine A. Behavioral assessment of the ability of intracerebral embryonic neural tissue grafts to ameliorate the effects of brain damage in marmosets. Mol Neurobiol 1994; 9: 207-223.

Roeser C, Cassel JC, Kelche C. Behavioral effects of GM1 ganglioside treatment and intrahippocampal septal grafts in rats with fimbria-fornix lesions. Exp Brain Res 1997; 115: 520-530.

Sass KJ, Buchanan CP, Westerveld M, Marek KL, Farhi A, Robbins RJ. et al. General cognitive ability following unilateral and bilateral fetal ventral mesencephalic tissue transplantation for treatment of Parkinson's disease. Arch Neurol 1995; 52: 680-686.

Segal M, Greenberger V, Pearl E. Septal transplants ameliorate spatial deficits and restore cholinergic functions in rats with a damaged septo-hippocampal connection. Brain Res 1989; 500: 139-148.

Sinden JD, Hodges H, Gray JA. Neural transplantation and recovery of cognitive function. Behav Brain Sci 1995; 18: 10-35.

Spencer DD, Robbins RJ, Naftolin F, Naftolin F, Marek KL, Vollmer T et al. Unilateral transplantation of human fetal mesencephalic tissue into the caudate nucleus of patients with Parkinson's disease. N Engl J Med 1992; 327: 1541-1548. Also see Comments on pages 1589-1590 and 1591-1592.

Steckler T, Sahgal A. The role of serotonergiccholinergic interactions in the mediation of cognitive behavior. Behav Brain Res 1995; 67: 165-199.

Vinogradova OS. Expression, control, and probable functional significance of the neuronal thetarhythm. Prog Neurobiol 1995; 45: 523-583. 
Wetzel W, Ott T, Matties H. Post-training hippocampal rhythmic slow activity ("theta") elicited by septal stimulation improves memory consolidation in rats. Behav Biol 1977; 21: 32-40.

Whitehouse PJ, Hedreen JC, White CL, Price DL. Basal forebrain neurons in the dementia of Parkinson disease. Ann Neurol 1983; 13: 243-248.

Will B, Duconseille E, Cassel JC, Knoops B, Van den Bosch de Aguilar P, Woerly S. Regeneration in brain and spinal cord. In: Ferretti $P$, Geraudie J, eds, Cellular and Molecular Basis of Regeneration: From Invertebrates to Human. New York: John Wiley \& Sons, 1998; 379-410.

Winkler J, Suhr ST, Gage FH, Thal LJ, Fisher LJ. Essential role of neocortical acetylcholine in spatial memory. Nature 1995; 375: 484-487.
Woerly S, Laroche G, Marchand R, Pato J, Subr V, Ulrich $\mathrm{K}$. Intracerebral implantation of hydrogel-coupled adhesion peptides: Tissue reaction. J Neural Transpl Plast 1995; 5: 245-255.

Woerly S, Maghami G, Duncan R, Subr V, Ulrich K. Synthetic polymer derivatives as substrata for neuronal adhesion and growth. Brain Res Bull 1993; 30: 423-432.

Woerly S, Pinet E, De Robertis L, Bousmina M, Laroche $G$, Roitback $T$ et al. Heterogeneous PHPMA hydrogel for tissue repair and regeneration in the injured spinal cord. J Biomat Sci, Polymer Ed 1998; 9: 681-711.

Woerly S, Plant GW, Harvey AR. Neural tissue engineering: from polymer to biohybrid organs. Biomaterials 1996; 17: 301-309. 

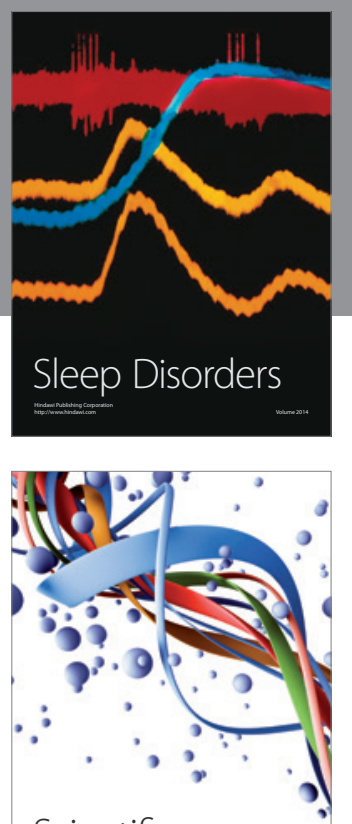

Scientifica
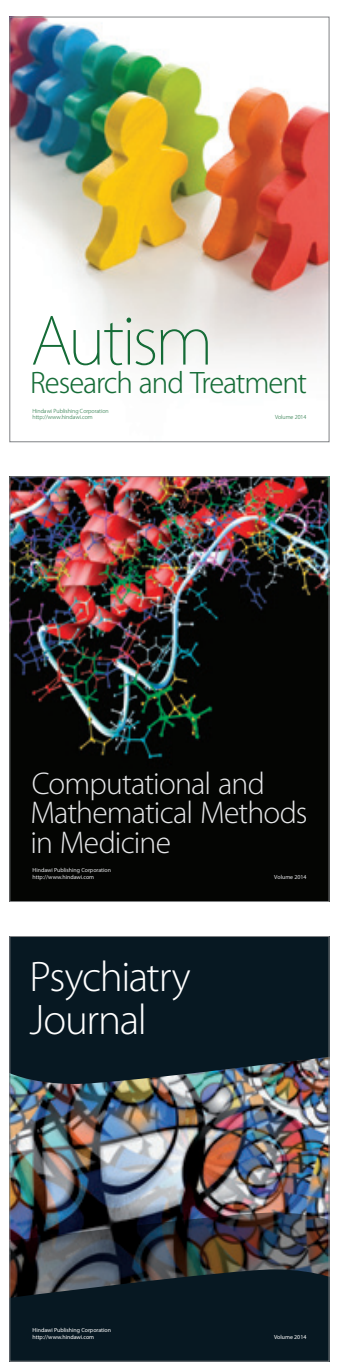
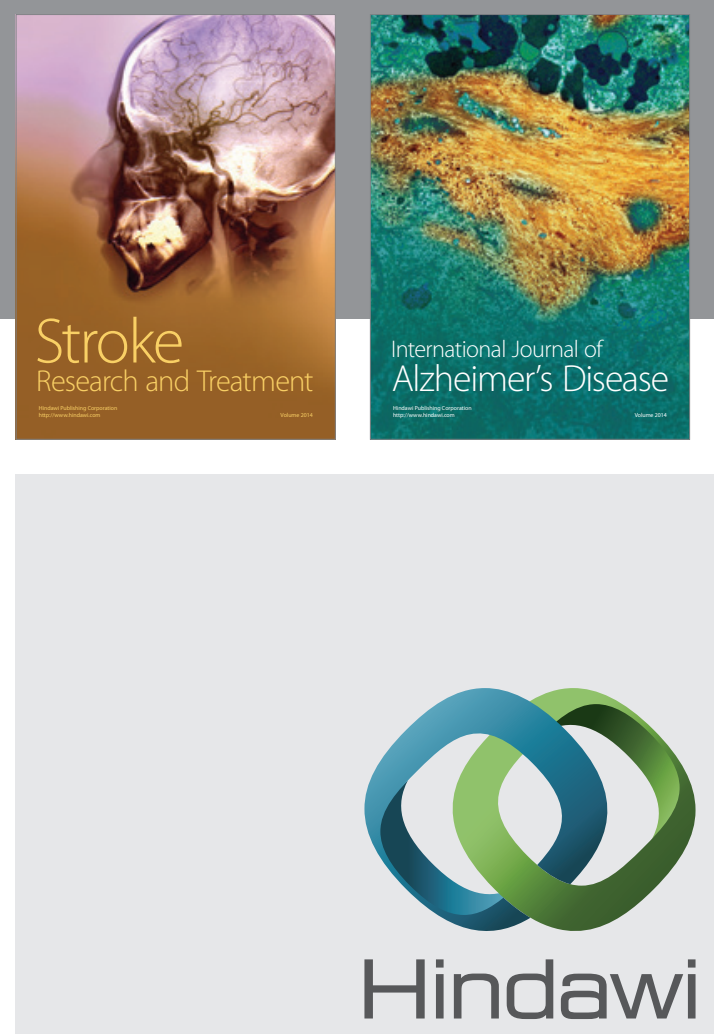

Submit your manuscripts at

http://www.hindawi.com
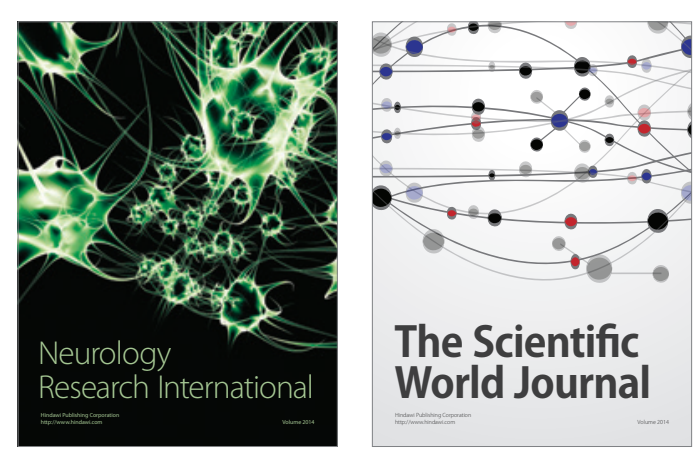

The Scientific World Journal

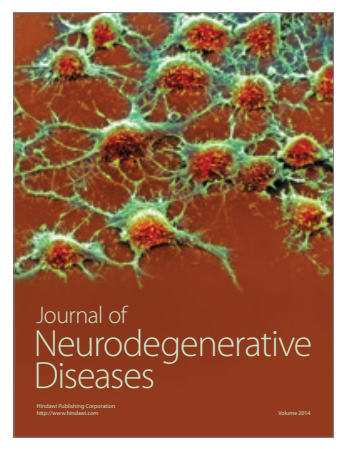

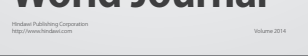

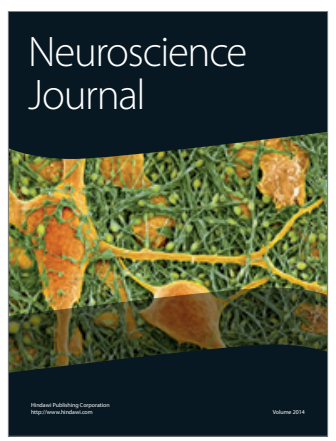

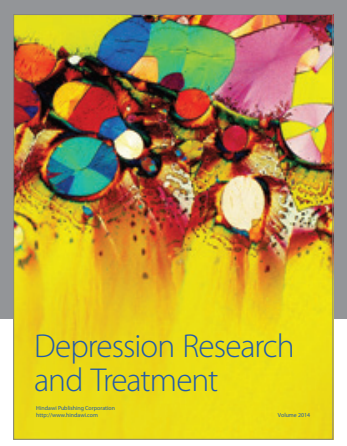
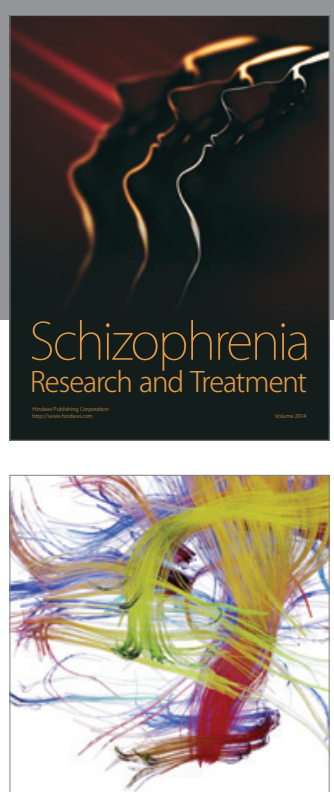

Brain Science

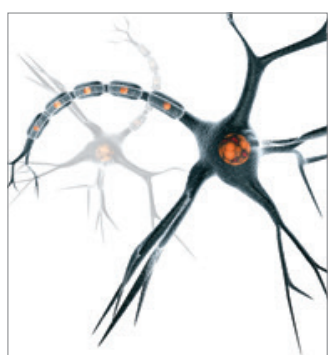

Neural Plasticity
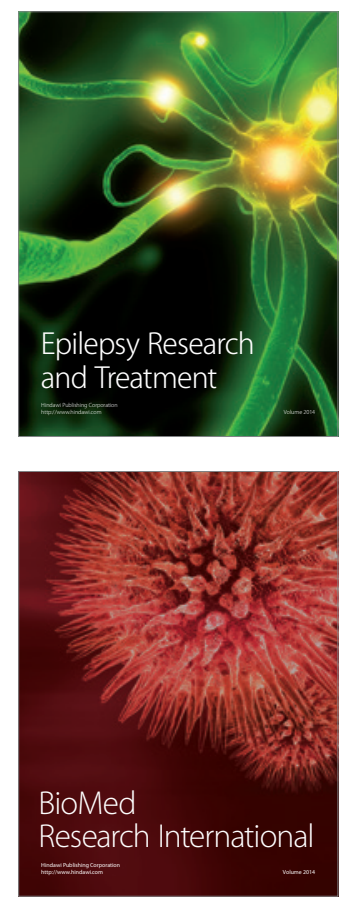

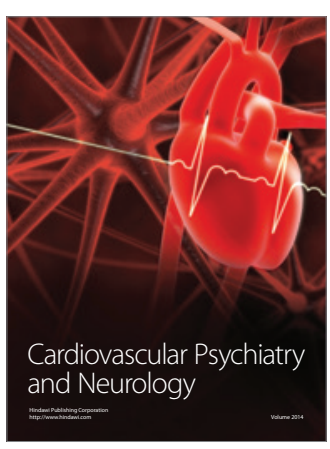

Parkinson's

Disease
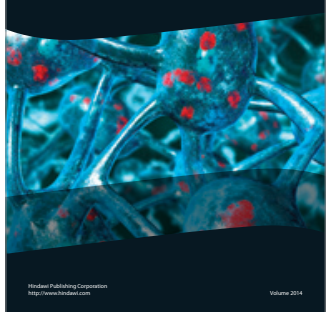